\title{
Clinical Profile, Risk Factors and Impact of Cerebral Palsy on Children in a Tertiary Hospital in Port Harcourt, Nigeria
}

\author{
West Boma Awoala, \\ Rivers State University Teaching Hospital, Nigeria \\ Onubogu Uchenna Chinweokwu, \\ Department of Paediatrics, Port Harcourt, Nigeria
}

Doi:10.19044/esj.2020.v16n9p337～URL:http://dx.doi.org/10.19044/esj.2020.v16n9p337

\begin{abstract}
Cerebral palsy is a common neurological problem that causes significant disabilities in children. Aim: To describe the clinical profile of children with cerebral palsy in Port Harcourt as well as to identify risk factors and its' impact. Methods: This was a 2 years prospective cross-sectional study in the Paediatric neurology clinic of the Rivers State University Teaching Hospital Nigeria. Children diagnosed with cerebral palsy and those whose parents gave consent were consecutively recruited into the study while their clinical information including laboratory findings was entered into a standard proforma. Results: Among the 296 children seen in the neurology clinic, $141(47.6 \%)$ had cerebral palsy. They were aged 6 months to 14 years, with a mean age of $3.07 \pm 3.5$ years and a $\mathrm{M}$ : F ratio of $1.6: 1$. They were mostly term babies $86(61.0 \%)$, delivered vaginally107(75.9\%) by unqualified attendants $74(52.5 \%)$ with normal birth weight 61(43.3\%) and 62(52.9\%) had microcephaly. The common identifiable risk factors for cerebral palsy were perinatal asphyxia $65(46.1 \%)$, past history of meningitis $48(34.0 \%)$ and neonatal jaundice $31(22.0 \%$ ) while the common co-existing neurologic disorders were seizure disorders $47(46.1 \%)$ and speech impairment $21(20.6 \%)$. Spastic quadriplegia 50(35.5\%) was the most frequent type of cerebral palsy seen and it was significantly associated with a past history of perinatal asphyxia $\mathrm{P}=0.03$ and prematurity 0.008 . Only $11(44.0 \%)$ of the 25 children who were eligible to attend school did so, out of which $9(81.8 \%)$ performed poorly. Conclusion: Cerebral palsy is a major cause of neurodisability in Port Harcourt and its common risk factors are preventable.
\end{abstract}

Keywords: Cerebral Palsy, Neurodisability, Spastic Quadriplegia, Nigeria, Children 


\section{Introduction}

Cerebral palsy(CP) describes a group of permanent disorders of movement and posture leading to limitation of activity attributed to nonprogressive disturbances in the developing brain (Nelson Textbook of Paediatrics, 2007). The injury to the developing brain may occur during the antenatal, perinatal or post-natal periods. This chronic disorder which has no cure is often associated with other co-morbid neurological conditions including epilepsy, intellectual disability, speech disorder, visual disorder and hearing disorder (Bax, Goldstein, Rosenbaum, Leviton, Paneth, 2005).

Cerebral palsy is a common neurological problem seen in children with incidence varying across different geographical areas. Globally, the prevalence is approximately 2-2.5 per 1000 live births (Sherell, Dagencus, Oskoui,2013 ;Johnson, 2002) while in Africa, it varies between 1.5 -10 per 1000 live births (Olney \& Wright,2006; cooper, 2002; El- Tallaway, Farghaly, Shehata, Metwally, Rageh, Abo-Elfetoh, 2011; Dambi, Jelsma, MLambo,2015).

It has been observed to be one of the major causes of childhood disabilities in both developed and developing countries (Badawi, Felix, Kurinczuk, Dixon, Watson, Keogh, Valentine, Stanley, 2005). In the developed countries, it has been attributed to the increased survival of preterm infants (Nelson, 2003) while in the developing counties, its majorly attributed to poor obstetric care such as birth asphyxia, severe neonatal jaundice as well as central nervous system infections among others (El-Said, Bessisso, Janahi, Habob, El-Shafie, 2002; Nottidge \& Okogbo, 1991). It is important to note that in a significant number of cases, no obvious cause is ascertained (Archer, Axton, Burns, Malcolm. Meadows, Narcol, 1990).

Cerebral palsy is diagnosed by clinical evaluation with or without the help of brain imaging. Early diagnosis is key to improved long term outcome through early identification of affected children with early intervention. Affected children usually require multidisciplinary management for life involving the paediatrician, neurologist, orthopaedic surgeon, physiotherapist, speech and occupational therapist etc. Such children also face stigmatization, lack of education, poverty, inadequate facilities for rehabilitative care as well as diminished educational oppurtunities (Lagunju, Oyinlade, Famosayo, 2016).

This study which is the first of its' kind in our centre was carried out to describe the clinical profile of children with cerebral palsy in Port Harcourt as well as to identify the risk factors and its' impact.

\section{Materials/methods}

This was a prospective cross-sectional study carried out over two (2) years, from March 2015 to February 2017 in the Paediatric Neurology clinic 
of the Rivers State University Teaching Hospital Nigeria. The weekly Paediatric neurology clinic is run by a consultant paediatrician with special interest in neurology and a resident doctor every Wednesday.

Rivers State University Teaching Hospital is one of the two tertiary hospitals in the state. It is owned by the Rivers State government in the SouthSouth geo-political zone in Nigeria. It is a 375 bedded hospital and serves as referral centre for all the government owned health centres, secondary health facilities, private hospitals and neighbouring states.

Referrals are usually received from the paediatric outpatient department, discharge cases from the paediatric in-patient wards as well as from primary health care centres, general hospitals, private health facilities and from neighbouring states.

Ethical approval was obtained from the Rivers State Health Research Ethics Committee and consent obtained from parents/care-givers after thorough explanation of the study.

Children aged 6 months to 17 years with history and clinical evaluation suggestive of cerebral palsy were consecutively recruited into the study. Diagnosis of cerebral palsy was made based on the history of abnormal posture and motor development with presence of abnormal neurologic signs localising the possible lesion to the developing brain. Diagnosis was made or confirmed only by the consultant in charge of the neurology clinic.

Information obtained from the patients included; history of the illness, developmental, pregnancy, birth, neonatal, post-neonatal history, past medical history, socio-demographic data, age at presentation, gestational age at birth, place of delivery and history of other neurologic co-morbidities such as epilepsy, speech defect, hearing defect amongst others.

Each patient recruited into the study had a thorough neurologic examination.

Social class was determined using the classification by Olusanya, Okpere and Ezimokhai (1985). The total social class ranged from 1-5 in order of descending privileges and divided into upper, middle and lower socioeconomic classes.

Brain imaging (magnetic resonance imaging) was requested for each patient recruited.

Data was entered into excel spread sheet and analysed using IBM SPSS statistics version 23. Results were presented in frequency tables, percentages and bar chats. $P$ values $\leq 0.05$ were considered significant at $95 \%$ confidence interval. 


\section{Results}

\section{Characteristics of children with cerebral palsy}

Among the 296 children seen in the neurology clinic, 141(47.6\%) had cerebral palsy. Their age ranged from 6 months to 14 years. Their median age was 1.4 years while the mean age was $3.07 \pm 3.5$ years. There were more males, $86(61.0 \%)$ than females with an M: F ratio of $1.6: 1$. Majority $88(62.4 \%)$ were urban dwellers who were the first to second born of their parents $101(71.6 \%)$ in middle class families $60(42.5 \%)$ and born to mothers whose highest level of education was primary $78(57.4 \%)$. Most were term babies $86(61.0 \%)$ delivered vaginally107 (75.9\%) by traditional birth attendants or unqualified attendants $74(52.5 \%)$. Majority of the children had normal birth weight $61(43.3 \%)$ and presented with microcephaly 62(52.9\%) Table 1.

Table 1: Characteristics of children with cerebral palsy

\begin{tabular}{|c|c|}
\hline Variables & Study population, $n=141(\%)$ \\
\hline \multicolumn{2}{|l|}{ Age (years) } \\
\hline 6 mths to 3 & $102(72.4)$ \\
\hline$>3$ to 6 & $14(9.9)$ \\
\hline$>6$ to 9 & $12(8.5)$ \\
\hline$>9$ to 12 & $11(7.8)$ \\
\hline$>12$ & $2(1.4)$ \\
\hline \multicolumn{2}{|l|}{ Gender } \\
\hline Female & $55(39.0)$ \\
\hline Male & $86(61.0)$ \\
\hline \multicolumn{2}{|l|}{ Residence } \\
\hline Urban & $88(62.4)$ \\
\hline Rural & $53(37.6)$ \\
\hline \multicolumn{2}{|l|}{ Birth order } \\
\hline $1^{\text {st }}$ to $2^{\text {nd }}$ & 101 (71.6) \\
\hline $3^{\text {rd }}$ to $4^{\text {th }}$ & $29(20.6)$ \\
\hline$>4^{\text {th }}$ & $11(7.8)$ \\
\hline \multicolumn{2}{|l|}{ Social class of parents } \\
\hline Upper class & $28(19.9)$ \\
\hline Middle class & $60(42.5)$ \\
\hline Lower class & $53(37.6)$ \\
\hline \multicolumn{2}{|l|}{ Motucation(n=136) } \\
\hline No formal education & $2(1.5)$ \\
\hline Primary & $78(57.3)$ \\
\hline Secondary & $2(1.5)$ \\
\hline Tertiary & $54(39.7)$ \\
\hline \multicolumn{2}{|l|}{ Place of delivery } \\
\hline Tertiary Hospital & $15(10.6)$ \\
\hline $\begin{array}{l}\text { Secondary health care } \\
\text { centres }\end{array}$ & $10(7.1)$ \\
\hline Primary health care centres & 21(14.9) \\
\hline Private hospitals & $21(14.9)$ \\
\hline TBA/Unqualified attendant & $74(52.5)$ \\
\hline
\end{tabular}

Gestational age at delivery 


\begin{tabular}{ll} 
Preterm & $10(7.1)$ \\
Term & $86(61.0)$ \\
Post date & $2(1.4)$ \\
Unknown & $43(30.5)$ \\
Mode of delivery & \\
SVD & $107(75.9)$ \\
C/S & $34(24.1)$ \\
Birth weight $(\mathbf{K g})$ & \\
$0-<2.5$ & $14(9.9)$ \\
$2.5-<4$ & $61(43.3)$ \\
$>4$ & $19(13.5)$ \\
Unknown & $47(33.3)$ \\
OFC percentile $(\mathbf{n}=\mathbf{1 1 7})$ & \\
$<3$ rd & $62(52.9)$ \\
3- $<97$ th & $12(10.3)$ \\
$>97$ th & $43(36.8)$ \\
\hline
\end{tabular}

\section{Risk factors of cerebral palsy}

The most common identifiable risk factor to cerebral palsy was perinatal asphyxia 65(46.1\%), followed by past history of meningitis $48(34.0 \%)$ and neonatal jaundice 31(22.0\%) Table II.

Table II: Risk factors of cerebral palsy

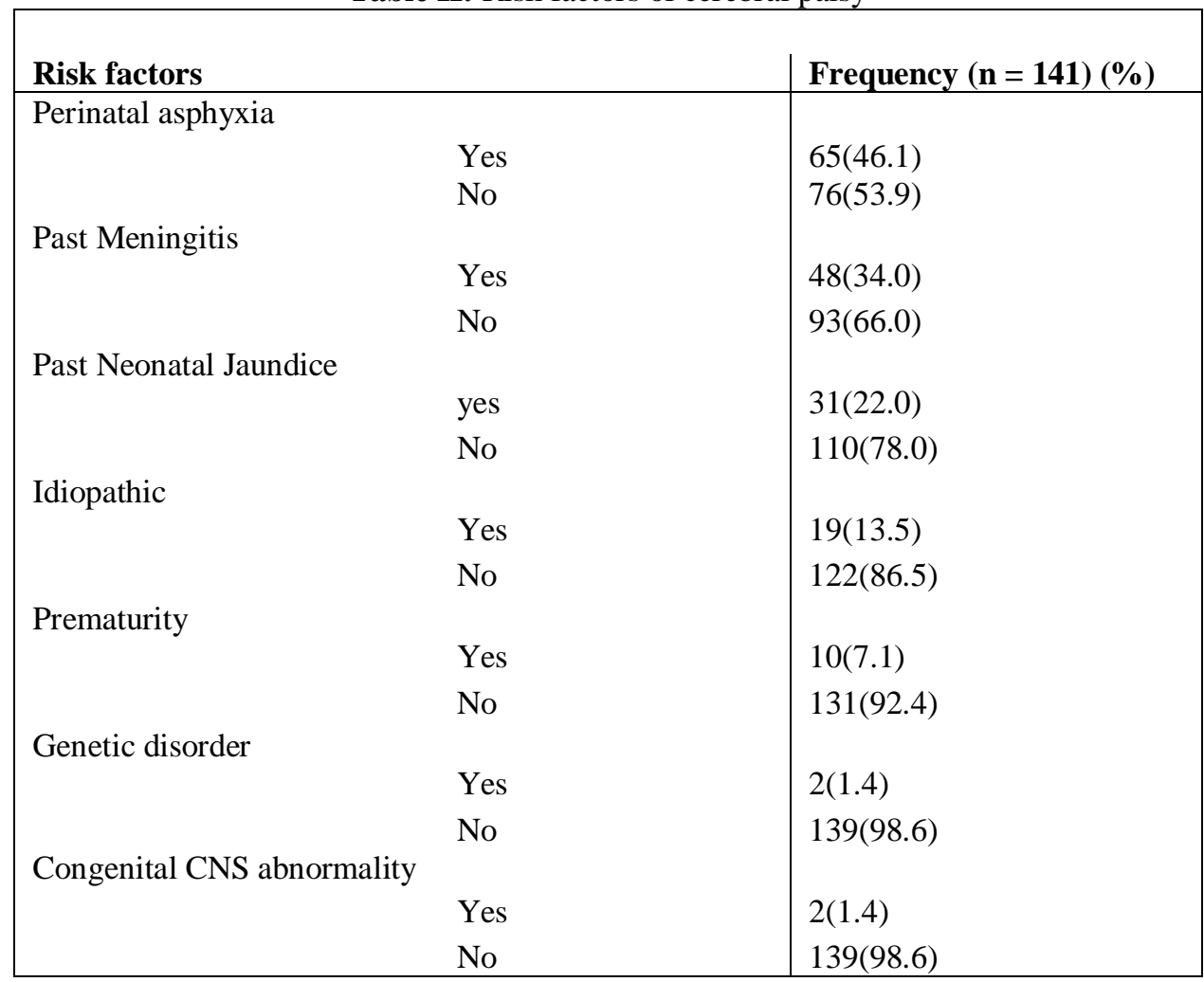




\section{Co-morbid conditions in children with cerebral palsy}

The commonest type of neurologic disorder co-existing with cerebral palsy was seizure disorder 47(46.1\%), followed by speech impairment $21(20.6 \%)$ while craniosynostosis $4(3.9 \%)$ was the least, Table III.

Table III: Co-morbid conditions in children with cerebral palsy

\begin{tabular}{ll}
\hline Co-morbid conditions & All patients, $\mathbf{n}=\mathbf{1 0 2}(\boldsymbol{\%})$ \\
\hline Seizure disorder & $47(46.1)$ \\
Speech impairment & $21(20.6)$ \\
Mental retardation & $7(6.7)$ \\
Hearing impairment & $7(6.7)$ \\
Attention deficit hyperactive disorder & $6(5.9)$ \\
Visual impairment & $5(4.9)$ \\
Movement disorder & $5(4.9)$ \\
craniosynostosis & $4(3.9)$ \\
\hline
\end{tabular}

\section{Types of cerebral palsy}

The most common type of cerebral palsy was spastic quadriplegia $50(35.5 \%)$, while the least was mixed type 2(1.4\%) Figure 1.

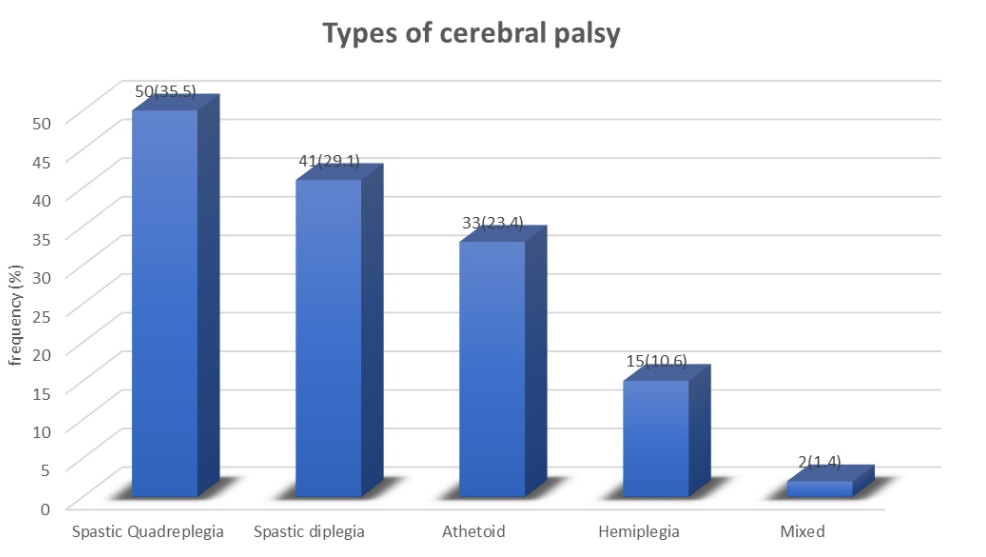

Figure 1: Frequency and types of cerebral palsy

\section{Association of the types of cerebral palsy with risk factors}

Only perinatal asphyxia and prematurity were significantly associated with spastic quadriplegia with $\mathrm{P}$ value 0.034 and 0.008 respectively (Table 4). 
Table 4: Association of the types of cerebral palsy with risk factors

\begin{tabular}{ccccccc}
\hline Variable & & Prevalence (\%) & P value & OD & 95\% & CI \\
\hline $\begin{array}{c}\text { Perinatal Asphyxia } \\
\text { Spastic Quadriplegia }\end{array}$ & Yes & $29(58)$ & 0.034 & 2.1 & 1.05, & 4.3 \\
& No & $21(42)$ & & & & \\
$\begin{array}{c}\text { Prematurity } \\
\text { Spastic Quadriplegia }\end{array}$ & Yes & $8(88.9)$ & 0.008 & 16.8 & 2.01, \\
& No & $1(11.1)$ & & & 141.0 \\
& & & & & \\
\hline
\end{tabular}

\section{Brain MRI result in patients with cerebral palsy}

Magnetic resonance imaging was done by only 13(9.2\%) children with cerebral palsy and the most common diagnosis was cerebral atrophy $6(46.1 \%)$.

Table 5: MRI Result of cerebral palsy

\begin{tabular}{|c|c|}
\hline MRI Result & $\mathbf{n = 1 3 ( \% )}$ \\
\hline Normal & $3(23.1)$ \\
Atrophy & $6(46.1)$ \\
Dystrophic Calcification & $1(7.7)$ \\
Gliosis & $1(7.7)$ \\
Hydrocephaly & $1(7.7)$ \\
Leukomalacia & $1(7.7)$ \\
\hline
\end{tabular}

\section{Impact of cerebral palsy on education}

Of 25 children with CP who were eligible for school, only 11(44.0\%) were attending school. The most common reason for non-school attendance was severity of illness $10(71.4 \%)$ and majority of their performance in school was poor $9(81.8 \%)$.

Table 6: Impact of cerebral palsy on education

\begin{tabular}{cc}
\hline Variable & $\mathbf{n}=\mathbf{2 5}(\mathbf{\%})$ \\
\hline School attendance & \\
Yes & $11(44.0)$ \\
Reason for non-school attendance $(\mathbf{n}=\mathbf{1 4})$ & $14(56.0)$ \\
Severity of illness & \\
Stigmatization and illness & $10(71.4)$ \\
School performance $(\mathbf{n}=\mathbf{1 1})$ & $4(28.6)$ \\
Average & $1(9.1)$ \\
Poor & $9(81.8)$ \\
Above average & $1(9.1)$ \\
\hline
\end{tabular}

\section{Discussion}

Cerebral palsy was observed in the present study to be a major cause of disability in childhood in Port Harcourt, Nigeria accounting for $47.6 \%$ of 
children attending the neurology clinic. This is comparable to the 50.3\% reported in Sagamu, Nigeria by Ogunseli, Ogundeyi, Ogunfowora and Olowu, (2008) but much higher than the 16.0\% and 16.2\% reported in Enugu, Nigeria (Izuora \& Ileoje, 1989) and India (Bhatia \& Joseph, 2000) respectively. This wide disparity in the prevalence of $\mathrm{CP}$ could be attributed to the fact that the latter studies were carried out over a decade earlier as well as varying geographic locations. A previous study in Port Harcourt on the pattern of neurological disorders observed CP to be the $2^{\text {nd }}$ commonest after seizure disorder (West \& Onubogu, 2019). This was also observed in Ibadan, Nigeria (Lagunju \& Okafor, 2009).

The present study revealed a male preponderance with a M: F ratio of 1.6:1. Similar findings were seen in other Nigerian studies (Adogu, Ubajaka, Egenti, Obinwa, Igwe,2016; Lagunju, Adedokun, Fatunde, 2006; Okike, Onyire, Ezeonu, Agumadu, Adeniran, Manyike, 2013; Ejeliogu, Yiltok, Fakunrin, 2017; Omole, Adegoke, Omole, Adeyemi, 2018) and a study done in Dar-Es-Salam by Kusanga, Verma, Bharskaran and Elangovan (2012). The reason for this male preponderance is uncertain. However, experimental studies in adult animals and adult patients with stroke indicate that sex hormones such as estrogens provide protection against hypoxic-ischemic injuries and the neonatal brain is also influenced by these hormones (Johnston \& Hagberg, 2007). It is also pertinent to know that males born very preterm appear to be more vulnerable to white matter injury and intraventricular hemorrhages than females which predispose them to CP (Johnston \& Hagberg, 2007).

Majority of children with CP presented in the $1^{\text {st }} 3$ years of life in the present study. This pattern was also observed in Sagamu (Ogunseli et al), Ibadan (Lagunju et al, 2006), Zaria (Sathiakuma \& Yakubu, 1987) in Nigeria and Dar-Es-Salam (Kusanga et al, 2012). This is not surprising as clinical manifestations of $\mathrm{CP}$ are usually apparent when the child delays in achieving keenly anticipated mile stones in early infancy necessitating hospital visits by anxious parents or care-givers.

More than half of children with $\mathrm{CP}$ dwell in urban areas. Similar observation was also made in Nnewi (Adogu et al, 2016), Nigeria were 42\% of CP cases resided in Urban areas. This could be attributed to the fact that specialized services required in the management of $\mathrm{CP}$ is mainly provided by tertiary hospitals which are usually situated in urban areas and thus not readily assessed by people living in rural areas who may be unable to assess them due to poor terrain, lack of transportation as well as funds.

Over two third of children with CP were $1^{\text {st }}$ and $2^{\text {nd }}$ born. First born were also observed to account for more than $2 / 3^{\text {rd }}$ of cases of CP in Osun State (Omole et al, 2018) and Zaria ( Sathiakuma \& Yakubu, 1987) in Nigeria. This is not surprising as primigravid women are more at risk of prolonged 
obstructed labour which may lead to birth asphyxia and subsequent CP (Indra, Usharani, Bendigeri, 2017). Hashim, Nagvi, Khanam and Jafry, (2012) in their study concluded that primigravids were a high risk factor for poor maternal and perinatal outcome as they were susceptible to prolong $2^{\text {nd }}$ stage labour and fetal distress.

Families of middle and lower socio-economic classes were mostly affected in the present study accounting for $42.5 \%$ and $37.6 \%$ respectively. A study in Jos (Ejeliogu et al, 2017), Nigeria observed that the families of lower socio-economic class were mostly affected. This trend was also observed in Sagamu (Ogunseli et al), Osun State (Omole et al, 2018), previous study in Port Harcourt (Frank-Briggs \& Alikor, 2011), Nigeria and in India (Pratibha,Munni, Gunmala, 2002). This is not surprising as families of lower socio-economic classes are usually less educated with less awareness, low income and may have lower paid jobs resulting in limited antenatal care and delivery services. A study by Thomas, Khathrim, Tianya, Sybille, Teresa, Hans, Bernhard, Matthias, Micheal, 2012), showed that socioeconomic status is inversely related to severity of diseases.

Children of mothers with primary level of education accounted for more than half of cases of $\mathrm{CP}$ in the present study. This finding however contrasts the study in Nnewi (Adogu et al, 2016) and Osun State (Omole et al, 2018) Nigeria were children of mothers with secondary education predominated. The finding in the present study corroborates with findings that high maternal education is associated with improved child health and reduced mortality (Sonalde \& Soumya, 1998).

Children delivered by Traditional birth attendants were mostly affected. Home delivery was also observed as the commonest place of delivery in Sagamu (Ogunseli et al, 2008) and Jos (Ejeliogu et al, 2017), Nigeria. This is because these women may not have benefitted from the services of skilled personnel as well as proper newborn resuscitation leading to sequelae. The preference for home and TBA deliveries could be due to ignorance, Poor education, poverty, traditional and cultural beliefs and practices, far distance to health facilities, inadequate transportation as well as high cost of these health facilities.

Identified commonest risk factor in the present study was birth asphyxia followed by past history of meningitis and severe neonatal jaundice accounting for $46.1 \%, 34.0 \%$ and $22.0 \%$ respectively. This pattern was also observed in other parts of Nigeria (Lagunju et al, 2016; Ogunseli et al, 2008; Adogu et al, 2016; Omole et al, 2018;Frank- Briggs \& Alikor, 2011; Lagunju \& Fatunde, 2009; Belonwu, Gwarzo, Adeleke, 2009). Birth asphyxia being the commonest cause of CP was also observed in Turkey (Erkin, Delialioglu, Ozei, Culha, Sirza, 2008). Reasons could be due to poor utilization of health services, ignorance, poor education as well as poor health service delivery 
particularly at the primary health centers, insufficient number of professional health workers and lack of basic obstetric and neonatal resuscitation equipments (Duru \& Sobaniec, 2003). In developed countries however, intraventricular hemorrhage is the commonest risk factor (Johnson, 2002; Ehrenkranz, Dusick, Vohr, Wright, Wrage, Poole, 2006). This disparity in the predisposing factor in developed countries can be attributed to the much higher survival rate of extremely low birth weight babies as compared to developing countries. In the present study, prematurity accounted for only $7.1 \%$ of cases. A study in Egypt, a lower middle income country just like Nigeria reported prematurity as the second commonest predisposing factor after birth asphyxia (El-Tallaway et al, 2011). The difference could be attributed to a better survival rate of extremely low birth weight babies.

It is pertinent to note that idiopathic causes accounted for up to $13.5 \%$ in the present study. In Ibadan, Nigeria (Lagunju et al, 2006), risk factors could not be ascertained in only $4 \%$ of cases. The very high percentage of idiopathic cases in the present study could be attributable to the fact that this information was obtained from their past medical history via direct interview of parents/care-givers which could be affected by their level of education. The idiopathic causes could also be due to intra-uterine infections which could not be readily diagnosed in our center or hypoglycemia that may not have been recalled by the parents/care-givers.

The commonest co-morbid condition is seizure disorder followed by speech disorder in the present study. Seizure disorder was also observed to be the commonest co-morbid condition in Sagamu (Ogunseli et al, 2008), Ibadan (Lagunju et al, 2006), Asaba (Okike et al, 2013), Jos (Ejeliogu et al, 2017), in a previous study in Port Harcourt (Frank-Briggs \& Alikor,2011), as well as in Poland (Kwak \& Sobaniec, 2003) and Sweden (Carlsson, Hargberg, Orsson, 2003). Contrary to the present study, speech impairment was the commonest co-morbid condition followed by seizure disorder in Osun state (Omole et al, 2018) whereas in India (Pratihba et al, 2002; Scrivatsava, Laisram, Srivatsava, 1992), intellectual disabilities was the commonest co-morbidity. The reason for this difference could be due to different geographic locations.

Spastic CP was observed to be the commonest type in the present study accounting for $64.6 \%$ of cases. This was comparable to the $64.9 \%, 72.7 \%$ and 75.0\% observed in Jos (Ejeliogu et al, 2017), Osun state (Omole et al, 2018), and Dar-Es-Salam, Tanzania (Kusanga et al, 2012) respectively. This was however lower than the $80.4 \%$ and $83.5 \%$ observed in Sagamu (Ogunseli et al, 2008) and Ibadan (Lagunju et al, 2006) Nigeria. Quadriplegic CP was the commonest topographic distribution in the present study followed by diplegic CP. Quadriplegic CP was also observed as the commonest type in Sagamu (Ogunseli et al, 2008), Osun state (Omole et al, 2018) and Kano state (Belonwu et al, 2009) in Nigeria. 
More than half of children with CP were not attending school in the present study. This was also observed in a similar study in Ibadan (Lagunju et al, 2016). In the present study the reason for non-school attendance was majorly due to severity of the illness. It was also observed that more than threequarters of cases in the present study performed poorly in school. This is expected as up to $46.1 \%$ of children who had brain MRI done had atrophy of the brain which could be responsible for the poor school performance in these children.

\section{Conclusion}

Cerebral palsy is a major cause of neurodisability in Port Harcourt, Nigeria. Spastic CP is the commonest type implicated with quadriplegic CP being the commonest topographic type and seizure disorder, the commonest co-morbidity. Birth asphyxia, Meningitis and severe neonatal jaundice are the commonest risk factors to $\mathrm{CP}$ which are preventable. This therefore calls for general improvement in the perinatal care services in Nigeria.

\section{References:}

1. Adogu POU, Ubajaka CF, Egenti NB, Obinwa AMJ, Igwe WC (2016). Evaluation of risk factors of Cerebral palsy in a tertiary health facility, Nnewi, Nigeria: a case-control study. Int J Med Sc Publ Health 5: 109-114

2. Archer MA, Axton MD, Burns T, Malcolm MD, Meadows MD, Narcol R (1990). Jolly's Disease of Children, $6^{\text {th }}$ edn. Oxford Blackwell Publishing Limited 320-327

3. Badawi N, Felix JF, Kurinczuk, Dixon G, Watson L,Keogh JM, ValentineJ, Stanley FJ (2005). Cerebral palsy following term newborn encephalopathy; a population based study. Dev Med Child Neurol 47: 293-298

4. Bax M, Goldstein M, Rosenbaum P, Leviton A, Paneth N (2005). Proposed definition and classification of cerebral palsy. Dev med child neurol 47: 571-576

5. Belonwu RO, Gwarzo GD, Adeleke SI (2009). Cerebral palsy in Kano, Nigeria-a review. Niger J Med 18: 186-189

6. Bhatia M, Joseph B (2000). Rehabilitation of cerebral palsy in a developing country: the need for comprehensive assessment. Paediatr Rehabil 4: 83-86

7. Carlsson M, Hargberg G, Olsson I (2003). Clinical and aetiological aspects of epilepsy in children with cerebral palsy. Dev Med Child Neurol 45: 371-376

8. Couper J (2002). Prevalence of Childhood disability in rural Kwa Zulu-Natal. S Afr Med J, 92: 549-552 
9. Dambi JM, Jelsma J, MLambo T (2015). Caring for a child with Cerebral palsy: The experience in Zimbabwean mothers. Afr J Disabil 4: 168-178

10. Duru EJ, Nwagbos CI (2007). The problems and prospects of public health care development in Nigeria's local government system. Glob J Soc Sci 6: 51-56

11. Ehrenkranz RA, Dusick AM, Vohr BR, Wright LL, Wrage LA, Poole WK (2006). Growth in the neonatal intensive care unit inflences neurodevelopmental and growth outcomes of extremely low birth weight infants. Paediatr 117: 1253-1261

12. Ejeliogu EU, Yiltok ES, Fakunrin AOD (2017). Clinical profile of children with cerebral palsy in Jos, North-central Nigeria. Intern Neuropsych Dis J 2017; 9: 1-8

13. El-Said MF, Bessisso MS, Janahi MA, Habob LH, El-Shafie SS (2002) . Epidemiology of neonatal meningitis in Qatar. Neurosciences(Riyadh) 7:163-166

14. El-Tallawy HN, Farghaly WM, Shehata GA, Metwally NA, Rageh TA, Abo-Elfetoh. (2011). Epidemiology of cerebral palsy in ElKharga district new valley (Egypt). Brain Dev 33: 406-411

15. Erkin G, Delialioglu SU, Ozei S, Culha C, Sirza H (2008). Risk factors and clinical profile in Turkish children with cerebral palsy: analysis of 625 cases. Int J Rehabil Res 2008; 31: 89-91

16. Frank-Briggs A, Alikor EAD (2011). Sociocultural issues and causes of cerebral palsy in Port Harcourt, Nigeria. Niger J Paediatr 38: 115-119

17. Hashim N, Nagvi S, Khanam M, Jafry HF (2012). Primiparity as an intrapartum obstetric risk factor. J Pak Med Assoc 62: 694-698

18. Indra, Usharani N, Bendigeri M (2017). A study on clinical outcome of obstructed labour. Int J Reprod Contracept Obstet Gynecol 6: 439-442

19. Izuora GI, Ileoje SO (1989). A review of neurological disorders seen at the Paediatric neurologic clinic of the university of Nigeria Teaching Hospital, Enugu. Ann Trop Paediatr 4: 185-190

20. Johnson A (2002). Prevalence and characteristics of children with cerebral palsy in Europe. Dev med child neurol 2002; 44: 633-640

21. Johnston MV (2007). Encephalopathies In: Kliegman RM, Stanton BMD, Behrman R, Geme JS, Schor N (ed). Nelson Textbook of Pediatrics. $20^{\text {th }}$ ed, St Loius MO. WB Saunders Co; 598; 28962899

22. Johnston MV, Hagberg H (2007). Sex and the pathogenesis of Cerebral Palsy. Dev Med Child Neurol 49: 477-478 
23. Kisanga AO, Verma A, Bharskaran AA, Elangovan M (2012). Prevalence of cerebral palsy in children (under-five) in and around Dar-Es-Salam. IMTU Med J

24. Kwak W, Sobaniec W (2003). Risk factors and prognosis of epilepsy in children with cerebral palsy in North Eastern Poland. Brain Dev 2003; 25: 499-506

25. Lagunju IA, Adedokun BO, Fatunde OJ (2006). Risk factors for epilepsy in children with cerebral palsy. Afr J Neurol Sci 2006; 25: 29-37

26. Lagunju IA, Fatunde OJ (2009). The child with cerebral palsy in a developing country-diagnosis and beyond. J Pediatr Neurol 7: 375379

27. Lagunju IA, Okafor AA (2009). An audit of neurological disorders seen at the Paediatric neurology clinic, University College Hospital, Ibadan, Nigeria. West Afr J Med 28:38-42

28. Lagunju IA, Oyinlade O, Famosayo A (2016). Cerebral palsy in Nigerian children: Profile and impact on educational oppurtunities. DMCN 58: 20-24

29. Nelson KB (2003). Can we prevent Cerebral Palsy? New Eng J 349: 1765-1769

30. Nottidge VA, Okogbo ME (1991). Cerebral Palsy in Ibadan, Nigeria. Dev Med Child Neurol 33: 241-245

31. Ogunseli T, Ogundeyi M, Ogunfowora O, Olowu A (2008). Socioclinical issues in cerebral palsy in Sagamu, Nigeria. South Afr J Child Health 2008; 2: 120-124

32. Okike CO, Onyire BN, Ezeonu CT, Agumadu HU, Adeniran KA, Manyike PC (2013). Cerebral palsy among children seen in the neurology clinic of Federal Medical Centre (FMC) Asaba. J Community Health 2013; 38: 257-260

33. Olney SJ, Wright MJ (2006). Cerebral palsy In: Campbell SK, Vander-Linden DW, Palisano RJ eds. Physical therapy for children. St Louis: Saunders-Elsevier 625-664

34. Olusanya O, Okpere E, Ezimokhai M (1985). The importance of socio-economic class in voluntary fertility control in a developing country. W Afr J Med 4: 205-212

35. Omole JO, Adegoke SA, Omole KO, Adeyemi OA (2018). Pattern of cerebral palsy seen in children attending the outpatient paediatric physiotherapy clinics in Osun State tertiary hospitals in Nigeria. S Afr J Child Health 12: 52-57

36. Pratibha D S, Munni R, Gunmala S (2002). Clinical spectrum of cerebral palsy in North India-an analysis of 1000 cases. Trop J Pediatr 48: 162-166 
37. Sathiakumar N, Yakubu AM (1987). Cerebral palsy in Zaria, Northern Nigeria-Is it preventable? J Trop Pediatr 334: 263-265

38. Sherell M, Dagencus L, Oskoui M (2013). The epidemiology of cerebral palsy; New perspectives from a Candian Registry. Semin Pediatr Neurol 20: 60-64

39. Sonalde D, Soumya A (1998). Maternal education and child health: Is there a strong causal relationship? Demography 1998; 35: 71-81

40. Srivatsava VK Laisram N, Snvatsava RK (1992). Cerebral palsy. Indian Pediatr 29: 993-996

41. Thomas B, Kathrin H, Tianya Z, Sybille S, Teresa B, Hans J S, Bernhard MG,Matthias O, Micheal L (2012). Socioeconomic status, severity of disease and level of family members' care in adult surgical intensive care patients: the prospective ECSSTASI study. Intensive care Med 38: 612-619

42. West BA, Onubogu UC (2019). Pattern and predisposing factors of neurological disorders in a neurology outpatient clinic in Port Harcourt, Nigeria. Med Res Chronicles 6: 218-228 